
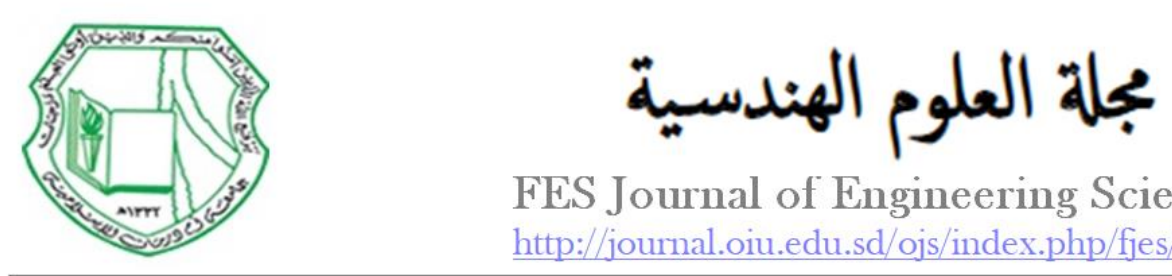

\title{
Applicability of using the 3D concrete printing technology in Sudan
}

\author{
Ruaa Elnaeem ${ }^{1},{ }^{*}$ and Mohammed Taglsir ${ }^{1}$ \\ 1 Civil Engineering Department, University of Khartoum, Khartoum, Sudan \\ * Corresponding author: Ruaa Elnaeem (e-mail: ruaa.elnaeem@gmail.com). \\ Article history: Received 14 March 2020, Received in revised form 4 November 2020, Accepted 11 November 2020
}

\begin{abstract}
Three-dimensional (3D) Printing is an advanced manufacturing process that has been applied to many fields. Recently, the 3D Concrete Printing (3DCP) has been employed for construction due to its ability to produce complex shapes easily, with less human intervention and with minimum material wastage. However, there are challenging issues regarding the cost of construction and the components of concrete mixture which are not fully explored. The aim of this paper is to review the 3DCP technology and investigate the possibility of applying it in Sudan, specifically for low-cost housing. In order to meet this aim, a comprehensive review has been done to study the projects implemented worldwide using 3DCP technique. Then, some concrete mixtures have been reviewed analyze the amount of materials used in each mix. The necessary tests to ensure the, workability, Extrudability and buildability have also been specified. Then the 3DCP technique has been compared with three common construction methods in Sudan for low-cost housing those were 40 square meters area in plan. These methods are the cement blocks, the Ferrocement and the graded sand mixture.. The comparison has been made in terms of construction cost, construction duration and the man-force required. The results have shown that the 3DCP model needed the least number of construction days. However, it was the highest in terms of the cost and the second best in terms of the used labors. It has been concluded that applying 3DCP technology in Sudan is possible and could be effective in the low-cost housing projects.
\end{abstract}

Keywords: Additive manufacturing (AM), Printing materials, 3D Concrete Printing (3DCP).

\section{INTRODUCTION}

$3 \mathrm{D}$ concrete printing $(3 \mathrm{DCP})$ is an emerging technology that combines digital technologies and new insights from materials technologies to allow construction without the use of formwork [1]. The formworks, used in concrete, leads to many consequences, such as, high material, labours and machineries cost, the time delays, its negative impact on the environment since most of it will be discarded now or then as waste. Those consequences with the low productivity, the limited geometrical freedom, the slow speed of construction and the low sustainability form challenges needed to be overcome by the construction industry. A rapid development has been witnessed in the last few years in the 3D printing technology in the used techniques and the used materials. According to the Index for risk management (INFORM), the United Nation system to observe disasters for each country out of 10, Sudan has problems with the local unrest, drought, floods and flash floods. Each hazard makes Sudan spends a significant budget in the response and the rehabilitation processes [2].

Another fact is that, Sudan has approximately $47 \%$ of its population under the poverty line, according to the World Bank statistics data, thus, a low economical status. As a result, having a house in Sudan in any of the major cities is difficult for most of the population[3].

The paper will focus on giving a review of the 
3D concrete printing and the previous studies which have been done, and the possibility of applying the technique in Sudan. The paper will discuss different construction models which are used in Sudan and compare it to the 3D printing technology in terms of time, cost and the used man-force.

\section{CURRENT 3DCP PROJECTS AROUND THE WORLD}

The 3D printing began to be developed in the 1980s [4] , and Since 1997 Many groups have been involved with the development of large-scale Additive manufacturing (AM) for construction applications . In 2014, WinSun produced 10 small full-size prefabricated homes as shown in Fig 1, in just one day. Each home measured 20 square meter, and cost $\$ 4,800$ to build [4]. After that, they built the highest 3D printed building, a five-story apartment and the world's first 3D printed villa (1100 $\mathrm{m}^{2}$ floor area).

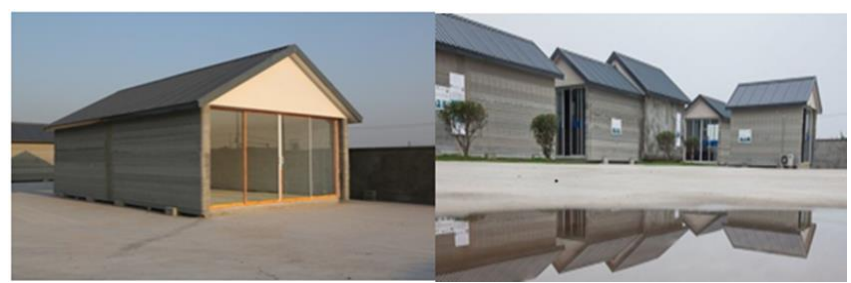

Fig. 1. Small houses constructed from 3D-printed building blocks by winsun [5].

In 2016 Apis Cor printed a small house onsite in Russia using their 3D printer in less than 24 hours Fig 2. The total price of the home was US $\$ 10,134$ which didn't include the cost of furnishings or appliances. All the walls and foundations of this structure were printed with a concrete mixture, needed only two people onsite to operate the printer and place reinforcement between the printed layers [6].

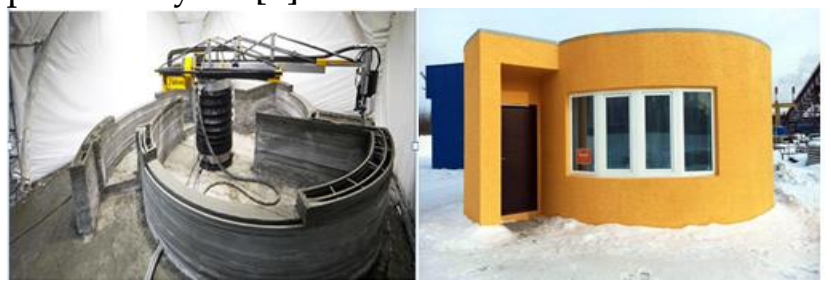

Fig. 2. First house printed by Apis Cor [7].

in 2018 The first project that have been completed by a company called ICON was as shown in Fig 3, when it built a $32.5 \mathrm{~m} 2$ building with a cost of $10,000 \$$. Moreover, recently the company has started its trial to build 50 houses for low income families in Latin America with a very low cost of construction Fig 3 [8].

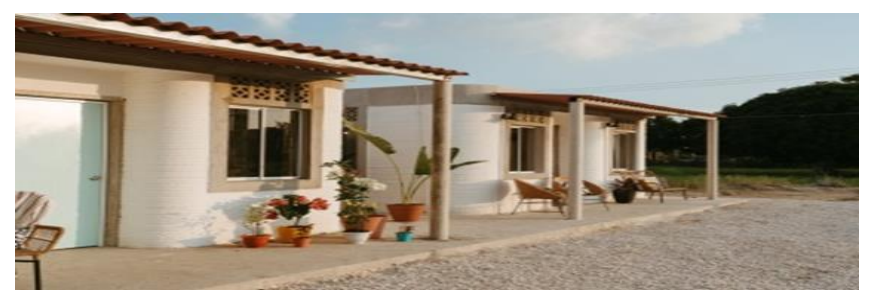

Fig. 3. houses which 3D printed by ICON and New Story in Latin America [8].

\section{ADVANTAGES AND LIMITATIONS OF 3D PRINTING OF CEMENTITIOUS MATERIAL}

The advantages can be detailed as follows:

\section{A. Mass Production}

The 3DCP does not require any formwork, or large amounts of labors.

\section{B. Customization}

With 3D printing it is possible to remove the limitations of formwork and other kinds of casting.

\section{Quality Control}

As the printing is always visible it is possible to correct errors as soon as they occur.

\section{Speed}

it is possible to have a $3 \mathrm{D}$ printer running overnight with only minimal supervision leading to significant savings in time.

\section{E. Pre-Casting}

3D Printing has significant applicability in precast construction as well.

\section{F. Elimination of Formwork}

Form work represents a significant cost of the construction of any element and also represents the most time consuming activity in construction [9].

\section{Limitations of $3 D P$}

\section{$A$. The sheer size of the printers}

This restricts the scale of building and project that could be printed.

\section{B. Expensive}

Due to high cost of 3D printer [6]. Although time and cost savings could be obtained in the future [9].

\section{Material}

Currently, a limited number of materials have been used. Also 3D printers are only capable of printing one material at a time [6],[10]. 


\section{Building codes and regulations}

Most building codes and procurement standards do not mention the 3DP technology.

\section{E. Shear and Seismic Strength}

Printed elements have weaker shear strength along the boundaries between two adjacent layers and elements such as columns become vulnerable to failure along those axes. The structures have also not been evaluated for their response to seismic loads [9].

\section{F. Implementing reinforcement}

Methods for including reinforcements are not well explored [9].

Recently, the companies have started to overcome many problems and obstacles that may hinder the development progress of the 3DCP use in construction.

\section{MATERIAL CRITERIA OF CONCRETE FOR 3DCP}

\section{A. Raw materials and chemical additives}

The concrete material for 3D printing shall mainly comprise of powder materials to meet the required printability .A few of cementations materials for 3DCP have been explored for construction applications as follows:

- Silica fume (SF): Enhancing workability and strength.

- Fly ash: Densifing the cement matrix and improvement of mechanical strength.

- Blast furnace slag: Enable high performance concrete.

- Limestone filler: modify the packing density improve the workability.

- Nano-silica: Enhancing the workability, strength and durability. Increase the water requirement. less flow ability, more cohesive and viscous [11].

Another approach to optimize the concrete material for 3D printing is employing chemical additives [11].

\section{B. Mix design for 3DCP}

The printing process requires specific fresh properties for cementations materials [12], the cementations material should keep favorable flow ability, extrudability, build ability, enough strength and low shrinkage, and must be designed to conform to the design of the $3 \mathrm{D}$ printer Fig 4.

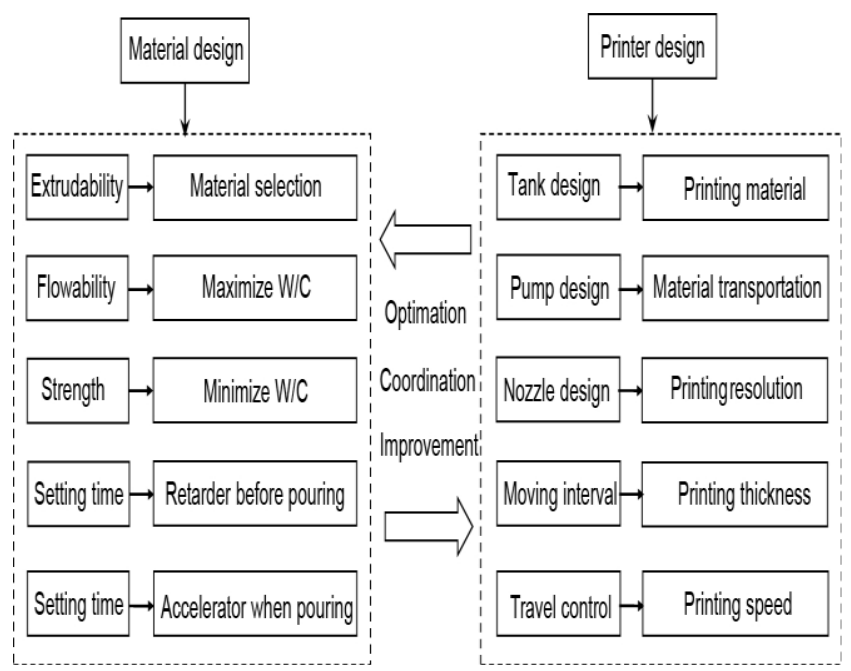

Fig. 4. General requirements in the mix design of cementitious mixture [13].

The mix that is labeled "optimal" should be able to meet certain target goals, as listed in Fig 5 .

Maximize compressive

Maximize workability

strength

\begin{tabular}{l|l|l}
\hline $\begin{array}{l}\text { Maximize flowability in } \\
\text { the system }\end{array}$ & $\begin{array}{l}\text { Maximize buildability } \\
\text { upon pouring } \\
\text { Maximize speed of } \\
\text { concrete setting }\end{array}$ & $\begin{array}{l}\text { Maintain appropriate } \\
\text { setting rate so as to } \\
\text { ensure bonding with } \\
\text { the subsequent layer }\end{array}$ \\
\hline
\end{tabular}

Fig. 5. Mix goals [23]

\section{The mix proportions}

Currently, there is no unified guideline or suggested procedure for designing and testing printing mixtures. Limited studies have provided an initial understanding of some of the desirable properties of printing concrete, extensive research and experimental data is still needed. Specifically, characterization of the fresh-state behavior of a printing mixture requires more investigation [14].

There were many studies have been done regarding the mix proportions and the cement content. Zeina Malaeb study [15] had the maximum cement content with $950 \mathrm{KG}$ in the mix, while Todd S. Rushing study [16] gave the minimum with $474 \mathrm{KG}$.

\section{THE APPLICABILITY OF USING THE 3DCP TECHNOLOGY IN SUDAN \\ - The Sudanese experience (Low cost housing)}

\section{A. The cement blocks houses}

The Sudanese housing and development fund (HDF) is a governmental entity implements low cost houses with the same designs and materials 
under the name popular housing. The HDF follows the traditional construction method by using the reinforced concrete, sand, cement and cement blocks as construction materials.

\section{B. The Ferrocement Houses}

Brouj Co.Ltd for Engineering and industrial consultancy is a governmental company that has implemented more than 50000 houses for people who were affected by implementing a new dam in their territories. The company used the Ferrocement construction system as the suitable approach to match the limited budget and the number of needed houses.

\section{The Graded Sand Mixture Houses}

Dr. Gony Engineering Company is a private company which has created a new method of construction under the name," Graded Sand Mixture (GSM) walls casting using total formworks". The GSM is a mixture with 1:12 Cement/sand ratio, The company's data showed that only 12 hours were needed to unfix the formworks to have the dried walls which can reduce the construction time by 90 , the smooth walls surface will save the time and the cost of the plastering.

\section{COMPARISON BETWEEN THE FERROCEMENT, THE CEMENT BLOCKS, THE GRADED SAND MIXTURE AND THE 3DCP CONSTRUCTION METHOD}

The Comparison will be done in terms of cost, time and the used man-force. The cost of each model will be compared based on the unit price for the built area only, and the time will be compared based on the average construction time for each model, and the used man-force will be based on the actual labours used.

\section{$>$ The models have a cost which includes:}

- The Ferro cement model : the foundations, the walls, the roof, the doors, the windows, the plastering, the paintings and the lighting.

- The cement blocks model : the foundation, the walls and the concrete works for the beams and the slab and it does not include the finishing work and the electrical supplies.

- The graded sand model : the foundations, the walls, the roof, the doors, the windows, the plastering, the paintings and the lighting.

By assuming the mix proportion used in the construction is 1:2.3, cement: sand and the cement content is $718 \mathrm{KG} / \mathrm{m} 3$, the $3 \mathrm{D}$ printed model has a built area of $38 \mathrm{~m} 2$ that forms one room, a bath and a hall that has small open kitchen. The total cost of the model is $10,000 \$$, as it shown in Table (1) in details, with a unit price of $263.2 \$ / \mathrm{m} 2$, and the meter square cost of the 3D printed wall was $27 \$ / \mathrm{m} 2$. The model can be completed in 3 day.

TABLE I: The cost of 3DCP model in details

\begin{tabular}{|lc|}
\hline Construction details & Cost / US Dollars \\
\hline Foundation & 277 \\
\hline walls & 1624 \\
\hline wiring & 2434 \\
\hline Windows and doors & 242 \\
\hline Exterior finishing & 3548 \\
\hline Interior finishing & 831 \\
\hline \multicolumn{2}{|c|}{ The meter square cost of the 3D printed wall was $\mathbf{2 7} \mathbf{~ S / \mathbf { m } ^ { 2 }}$} \\
\hline
\end{tabular}

In case of applying the 3D printed model in Sudan there will be an extra expenses for the customs and transportation of the machine and other hidden expenses which can be estimated as $70 \%$ of the machine cost which is $250,000 \$$. By assuming the machine can implement 120 houses per year, with the 5 years guarantee of the company, there will be an additional cost added to the set cost of the house. Hence, the new 3D printed model cost will be 10,708.3\$ .

By comparing the 3D printed model with the Sudanese models, it is clearly seen that the 3D printed model area is larger than the built area of the rest of the models as it is shown in Fig 7.

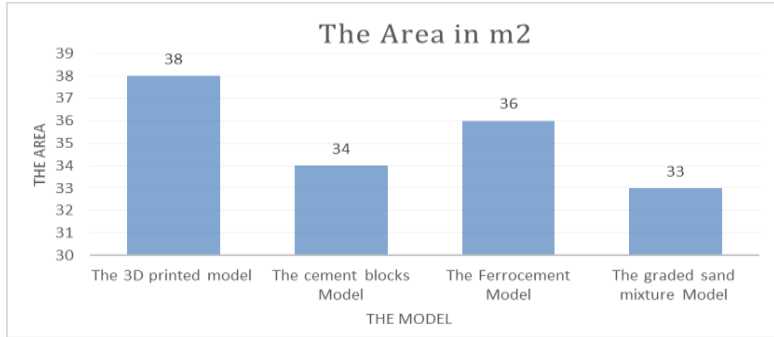

Fig 6: models areas in $\mathrm{m} 2$

Moreover, the 3D printed model has taken 3 days in the construction process, less than the spent time in the Ferro cement and the graded sand mixture models which had the same construction time by 7 days. While the cement blocks had an average of 18 days Fig 8 . 


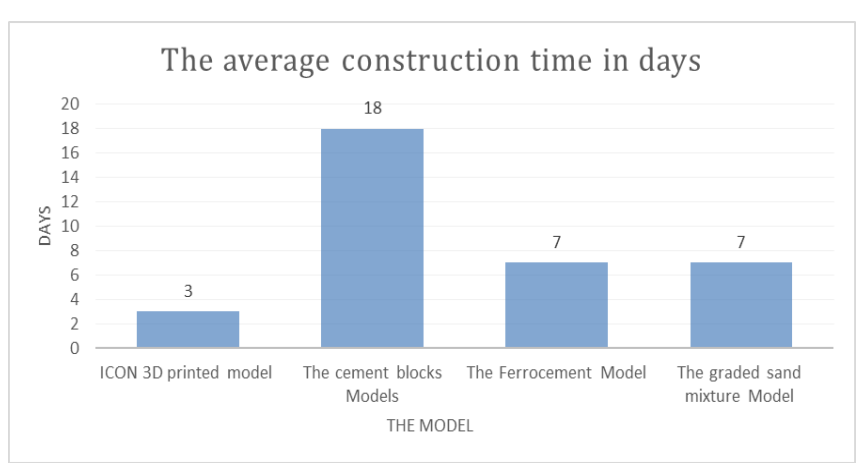

Fig 7: The models average construction time in days.

Similarly, the cement blocks and the graded sand mixture models used the same number of labours which was recorded as 25 labours for each. While the $3 \mathrm{D}$ printed and the Ferro cement models had approximately the same numbers in which they were 5 labours for the former and 4 for the latter, as it is explained in Fig 9.

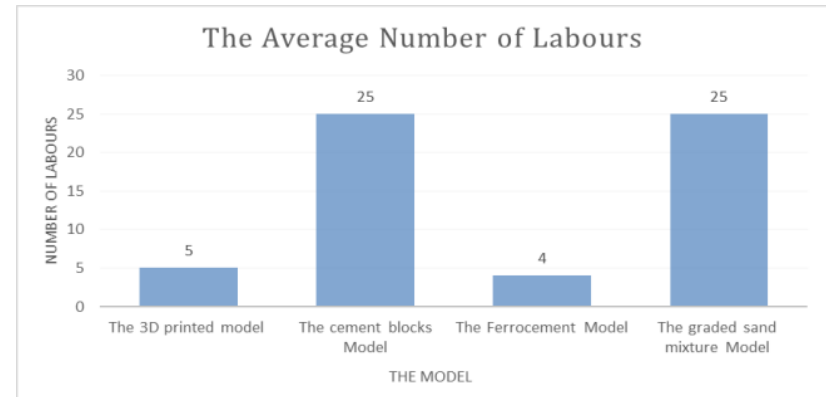

Fig 8: The average number of labours for implementing every model.

Moreover, the 3D printed model had the highest spent budget in the construction with a cost of 10,708.3 \$. Followed by the graded sand mixture model and the cement blocks model by $4950 \$$ and 2890 \$ respectively, while the Ferro cement model had the least budget between the 4 models with a cost of $2631.6 \$$, as it is illustrated in Fig 10.

Furthermore, by comparing the unit price for every model, it is clearly seen that the 3D printed model has the highest unit price with $281.8 \$ / \mathrm{m}^{2}$, followed by the graded sand mixture model with $150 \$ / \mathrm{m}^{2}$. The Ferro cement and the cement blocks model had the least unit prices with $73.1 \$ / \mathrm{m}^{2}$ and $85 \$ / \mathrm{m}^{2}$ respectively, as it is clarified in the Fig 11.

For more details, a comparison conducted on the walls meter square cost including the materials cost and the implementation cost without the finishing cost. It was found that the meter square cost of the $3 \mathrm{D}$ printed wall was 27 $\$ / \mathrm{m}^{2}$, the cement blocks cost was $15 \$ / \mathrm{m}^{2}$. While the Ferro cement was $12.9 \$ / \mathrm{m}^{2}$, and the graded sand mixture was $10 \$ / \mathrm{m}^{2}$. It is clear that the Ferro cement had the least cost among the 4 models followed by the cement blocks model and the 3D printed model. While the graded sand mixture model had the highest cost for the walls meter square cost, as it s shown in Fig 12.

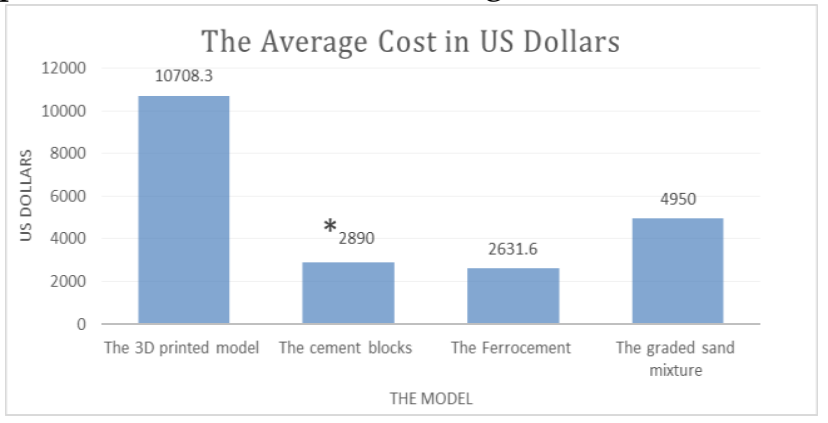

Fig 9: The models average cost in US dollars.

*The Cement blocks cost does not include the finishing which can be assumed $25 \$$ for the meter square

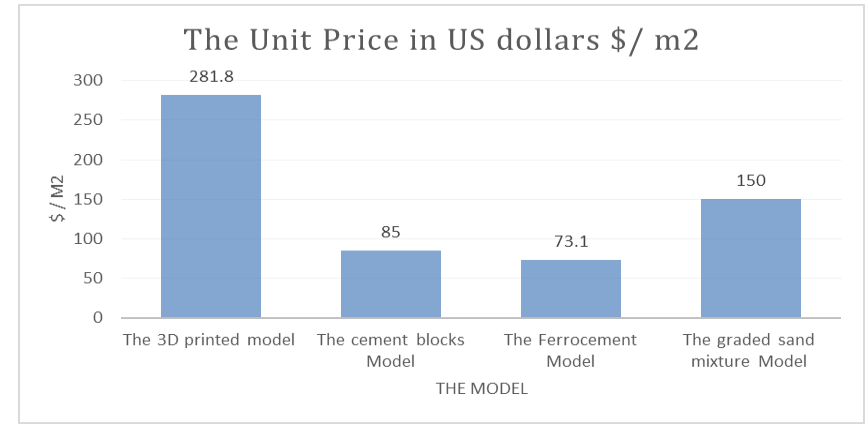

Fig 10: shows the models unit price in US dollars/m2

From the comparison, it is clear that the construction time and the used labours data were relatively low compared to other construction methods. For that, there is a possibility to apply the technology in Sudan in the disaster risk reduction plans in providing quick shelter for the affected people.

\section{CHALLENGES THAT MAY FACE THE APPLICATION OF THE 3D PRINTING IN SUDAN}

\section{A. Public persuasion \\ $B$. The machine price}

The machine prices are seen to be considerably high. Yet, the machine will not be just a one-time use equipment.

C. The skilled man-force to operate the machine

Most of the companies give two weeks training for the buyer's staff.

$D$. The materials

Many companies are looking for adapting local materials into the used mix. 


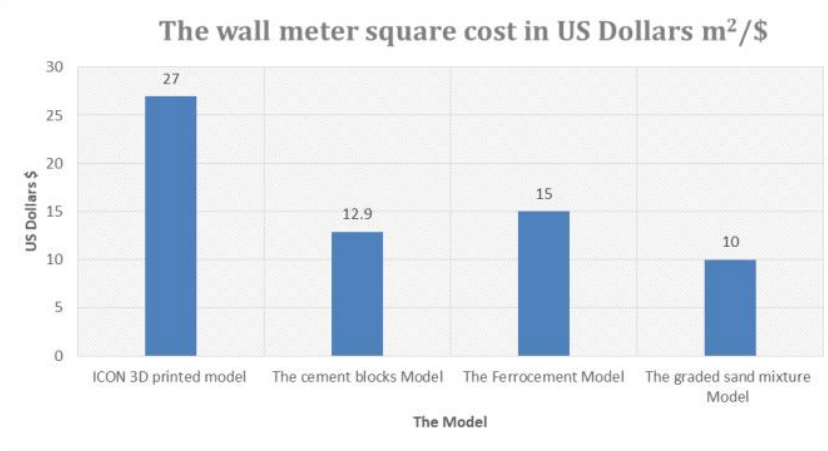

Fig 11: The models walls cost in US dollars/m2

\section{DISCUSSION}

The collected data and results indicate that there is a clear similarity between the $3 \mathrm{D}$ printing construction method and the Ferro cement construction method in terms of the construction time and the number of used labors. Moreover, the cost of the 3D printed model was the highest among all the models. The results suggest that the 3D printed model cannot be optimum to be adopted in Sudan, however, for the relative low construction time and the low number of the used man-force it could be put under consideration.

The reviewed researches showed that the materials used in 3D printing requires high powder content (mainly cement) starting from $474,552,718$ up to $950 \mathrm{~kg} / \mathrm{m}^{3}$ to achieve its properties. In some countries this content is acceptable in the concrete mixes, but because the hot weather in Sudan this will be problematic if cement content in the powder exceeded 400 $\mathrm{kg} / \mathrm{m}^{3}$.

The mix proportion which is 1:0.64:1.28 contains the lower amount of cement per meter cubic which is considered the most suitable mix to be used in Sudan with some additives to achieve its properties. That means some mix proportions with some development can be adopted in Sudan.

Some companies have used alternative materials like the natural additives, such as the agricultural waste, targeting the reduction of the cement amount and to adapt the local materials. Thus, making the 3D concrete printing materials locally available. The use of reinforcement differed from one company to another. There was a use of the normal reinforcement steel in some companies while others used the synthetic fibers.

When applying the technology in Sudan, the conflict may appear in the availability of the used materials in printing. Currently, some researches are being conducted to adapt the local materials and conditions to the mix design for making them affordable. The rarity of the used synthetic fibers in Sudan can be replaced by the traditional reinforcement steel.

Moreover, many researches have been conducted to find alternative materials to make the mix locally available and economically effective, and some companies have used some materials to reduce the cement proportion in the mix, such as the agricultural waste.

As the data was based on existed projects, it gives a clearer understanding of why the $3 \mathrm{D}$ technology has to be adopted in Sudan in the construction sector and the disaster risk reduction plan.

\section{CONCLUSION}

Extensive review has been done for some of the previous studies in the $3 \mathrm{D}$ concrete printing technology. Moreover, 3 used construction methods in Sudan were investigated, namely the cement blocks method, the Ferro cement method and the graded sand mixture, in terms of cost, time and used man-force. Then they were compared to the 3D concrete printing technology houses in the same terms. The main findings of this investigation can be drawn as follows:

- The reviewed studies do not follow one standard in determining the used mix until now, and it was found that there are some critical factors, namely the exrudibilty, the flowability, the buildability, the shrinkage and the setting time, should be controlled for the printing performance, and there are some tests should be done to evaluate those factors.

- It was found that the 3D concrete printing technology uses powder materials with different mix proportions that contain high cement content ranges from $474 \mathrm{KG} / \mathrm{m}^{3}-950 \mathrm{KG} / \mathrm{m}^{3}$.

- The comparison has led to find that the 3D printed house is effective in terms of time and the used man-force, while it was the highest cost among the 4 models. The results suggest that using the 3D technology in Sudan will provide many advantages in the construction sector and in the disaster risk reduction plans, for the low 
number of the used man-force and the short time

of implementing the 3D concrete printing facility.

\section{REFERENCES}

[1] J. G. Sanjayan and B. Nematollahi, 3D Concrete Printing for Construction Applications. Elsevier Inc., 2019.

[2] M. Version, Index for Risk Management. 2017.

[3] "Poverty \& Equity Data Portal." [Online]. Available: http://povertydata.worldbank.org/poverty/country/SDN.

[Accessed: 16-Feb-2020].

[4] C. Holt, L. Edwards, L. Keyte, F. Moghaddam, and B. Townsend, Construction 3D Printing, vol. 42, no. 3. Elsevier Inc., 2019.

[5] "About Winsun-Yingchuang Building Technique (Shanghai ) Co.Ltd. (WinSun)." [Online]. Available: http://www.winsun3d.com/En/About/. [Accessed: 16-Feb-2020].

[6] M. Sakin and Y. C. Kiroglu, "3D Printing of Buildings: Construction of the Sustainable Houses of the Future by BIM ScienceDirect ScienceDirect 3D Printing of Buildings: Construction of the Sustainable Houses of the Future by BIM Mehmet Sakin *, Yusuf Caner Kiroglu," in 34th International Symposium on Automation and Robotics in Construction (ISARC 2017), 2017, vol. 34, p. 8, doi: 10.1016/j.egypro.2017.09.562.

[7] "3D Printed Homes | Apis Cor | United States," Apis Cor. [Online]. Available: https://www.apis-cor.com. [Accessed: 16-Feb-2020].

[8] "Home I ICON BUILD." [Online]. Available: https://www.iconbuild.com/. [Accessed: 16-Feb-2020].

[9] .K. Baradi, "3D Printing as a Construction Process for Structural Members," Habitat Conclave Ahmedabad, vol. 67, p. 16, 2016.

[10] J. Kidwell, "Best Practices and Applications of 3D Printing in the Construction Industry," p. 8, 2017.

[11] G. Ma and L. Wang, "A critical review of preparation design and workability measurement of concrete material for largescale 3D printing," Front. Struct. Civ. Eng., p. 19, 2017, doi: 10.1007/s11709-017-0430-x.

[12] B. Lu et al., "A systematical review of 3D printable cementitious materials," Constr. Build. Mater., vol. 207, pp. 477-490, 2019, doi: 10.1016/j.conbuildmat.2019.02.144.

[13] M. A. Guowei, W. Li, and J. U. Yang, "State-of-the-art of 3D printing technology of cementitious material - An emerging technique for construction," 2018, vol. 475, pp. 475-495, doi: 10.1007/s11431-016-9077-7.

[14] T. S. Rushing et al., Investigation of Concrete Mixtures for Additive Construction. Elsevier Inc., 2019.

[15] Z. Malaeb, F. AlSakka, and F. Hamzeh, 3D Concrete Printing. Elsevier Inc., 2019.

[16] A. Kazemian, X. Yuan, R. Meier, and B. Khoshnevis, Performance-Based Testing of Portland Cement Concrete for Construction-Scale 3D Printing. Elsevier Inc., 2019. 